\title{
Dopamine and Noradrenaline in the Brain; Overlapping or Dissociate Functions?
}

\author{
Yadollah Ranjbar-Slamloo ${ }^{*}$ and Zeinab Fazlali2* \\ 'Eccles Institute of Neuroscience, The John Curtin School of Medical Research, The Australian National University, \\ Canberra, ACT, Australia, ${ }^{2}$ Department of Biomedical Engineering, Columbia University, New York, NY, United States
}

Dopamine and noradrenaline are crucial neuromodulators controlling brain states, vigilance, action, reward, learning, and memory processes. Ventral tegmental area (VTA) and Locus Coeruleus (LC) are canonically described as the main sources of dopamine (DA) and noradrenaline (NA) with dissociate functions. A comparison of diverse studies shows that these neuromodulators largely overlap in multiple domains such as shared biosynthetic pathway and co-release from the LC terminals, convergent innervations, non-specificity of receptors and transporters, and shared intracellular signaling pathways. DA-NA interactions are mainly studied in prefrontal cortex and hippocampus, yet it can be extended to the whole brain given the diversity of catecholamine innervations. LC can simultaneously broadcast both dopamine and noradrenaline across the brain. Here, we briefly review the molecular, cellular, and physiological overlaps between DA and NA systems and point to their functional implications. We suggest that DA and NA may function in parallel to facilitate learning and maintain the states required for normal cognitive processes. Various signaling modules of NA and DA have been targeted for developing of therapeutics. Understanding overlaps of the two systems is crucial for more effective interventions in a range of neuropsychiatric conditions.

Keywords: dopamine, noradrenaline, ventral tegmental area, Locus Coeruleus, co-transmission, neuromodulator, signaling

\section{INTRODUCTION}

Central nervous system produces diverse neurochemicals which bind to specific receptors coupled to the intricate intracellular signaling pathways. Synthesis and release of a primary neurotransmitter with a simplified action (e.g., excitatory or inhibitory) has been a ground for classification of neurons and synapses in the CNS. As knowledge of neurotransmission rapidly grew in the past few decades, it became soon clear that the actions of neurotransmitters are complex and some neurons produce and release two or more chemicals as fast neurotransmitters, neuromodulators, or neuropeptides (Vaaga et al., 2014). This often confounded the integration of connectivity knowledge with neurophysiology. Moreover, a single neurochemical can bind to different receptors and the receptor expression at the level of individual neurons are highly variable. For example, numerous metabotropic receptors have been identified for glutamate alone, with diverse distribution and function (Reiner and Levitz, 2018). Unlike glutamate and GABA 
which are known for their binding to the fast-acting ionotropic receptors, others predominantly activate metabotropic receptors, hence they are commonly called neuromodulators. These include monoamines such as noradrenaline (NA, also called norepinephrine), adrenaline (also called epinephrine), dopamine (DA), serotonin, and histamine. Monoamines are produced by small populations of neurons located in specific brain nuclei. These neurons project to widespread brain regions with numerous ramifications to broadcast specific signals about external stimuli and internal states.

The effect of neuromodulators on the target neurons is often mediated by G-protein coupled receptors. Multiple receptors may share a specific signaling pathway. Specificity of a neuromodulator then should depend on the source of release, concentration, efficacy, and the rate of depletion or reuptake from the extracellular space. Although the main neuromodulators, such as acetylcholine, dopamine, noradrenaline, and serotonin have a key role in controlling the brain states (Brown et al., 2012) and computations (Dayan, 2012), their interactions are yet mysterious. Dopamine and noradrenaline in particular, appear to significantly cross-talk in cortex and hippocampus (Devoto et al., 2006). Dopamine producing neurons are located in the midbrain nuclei; mainly ventral tegmental area (VTA) and substantia nigra pars compacta (Poulin et al., 2018). Noradrenergic nuclei are located in pons and medulla. Among these nuclei, LC contains the major proportion of the noradrenergic cells and targets multiple regions of the brain (Robertson et al., 2013). Although DA and NA have been studied as two separate systems, they overlap in multiple domains such as; shared biosynthetic pathway, co-release from noradrenergic terminals, innervation of similar area, non-specific receptor, transporter affinity, and shared intracellular signaling pathways (Figure 1). What are the functional consequences of these overlaps? In the following paragraphs, we expand the major domains of overlap and their neurophysiological and behavioral implications of such overlaps.

\section{VOLUME TRANSMISSION, RECEPTOR SIGNALLING, AND TRANSPORTER FUNCTIONS}

Neuromodulators such as DA, NA, and acetylcholine can diffuse far from the release site and activate receptors in a considerable distance from the terminal (Agnati et al., 1995; Fuxe et al., 2010). This process, which is known as volume transmission, can activate receptors as far as $8 \mu \mathrm{m}$ from the release site, in case of striatal dopamine (Sulzer et al., 2016). A long-range diffusion is also possible due to the circulation of the cerebrospinal fluid (CSF) along the peri-vascular space (Taber and Hurley, 2014). Peri-vascular CSF currents may supply neuromodulators far from their site of release, to activate receptors in area lacking direct projections.

Noradrenaline acts on three main G-protein coupled receptors, known as $\beta-, \alpha-1$, and $\alpha-2$ adrenoceptors (Figure 1C). These receptors have complex effects on neuronal excitability and synaptic transmission, depending on their site of action and concentration of NA (Berridge and Waterhouse, 2003;
Arnsten et al., 2012; Waterhouse and Navarra, 2019). $\beta$-adrenoceptors are coupled to $G_{s}$ which enhances cAMP signaling while $\alpha_{2}$-adrenoceptors are coupled with $G_{i}$ which suppresses adenylyl cyclase and reduces cAMP. Activation of presynaptic $\alpha_{2}$-adrenoceptors suppresses the synaptic release of neurotransmitters in various brain regions (Yavich et al., 1997; Nasse and Travers, 2014). $\alpha_{1}$-adrenoceptors activate phospholipase $\mathrm{C}$ signaling pathway through $\mathrm{G}_{\mathrm{q}}$. Dopamine acts on five types of $\mathrm{G}$-protein coupled receptors, $\mathrm{D}_{1}-\mathrm{D}_{5}$, which are categorized in two main functional classes of $\mathrm{D}_{1}$ and $\mathrm{D}_{2}$ (Beaulieu and Gainetdinov, 2011). $\mathrm{D}_{1}$-class of receptors comprises $\mathrm{D}_{1}$ and $D_{5}$ which are coupled to $G_{s}$ and enhance cAMP production $\left(D_{1}\right.$ and $\left.\mathrm{D}_{5}\right)$ and phospholipase $\mathrm{C}$ activity $\left(\mathrm{D}_{5}\right.$ or $\mathrm{D}_{1}: \mathrm{D}_{2}$ heterodimers, Figure $1 \mathrm{C}$ ). $\mathrm{D}_{2}$-class of dopamine receptors comprises $\mathrm{D}_{2}, \mathrm{D}_{3}$, and $D_{4}$. These receptors are coupled to $G_{i}$ and hence reduce the production of cAMP (Beaulieu and Gainetdinov, 2011). $\mathrm{D}_{1}$-class is expressed in the target cells, while $\mathrm{D}_{2}$-class is expressed in the presynaptic dopamine terminals as well as in the target cells (Beaulieu and Gainetdinov, 2011). $\mathrm{D}_{1}$-class of dopamine receptors share the same stimulating pathways which are used by the $\beta$-adrenoceptors (cAMP production) and $\alpha_{1}$-adrenoceptors $\left(\mathrm{G}_{\mathrm{q}}\right.$ and PLC, Figure 1C). $\mathrm{D}_{2}$-class share the pathways used by $\alpha_{2}$-adrenoceptors which involve inhibitory G-proteins (Beaulieu and Gainetdinov, 2011; Schmidt and Weinshenker, 2014). Dopamine can directly activate $\alpha_{2}$-adrenoceptors in LC and hippocampus (Guiard et al., 2008; El Mansari et al., 2010). Therefore, dissociation of DA and NA functions is particularly hard in areas with high concentrations of both, such as prefrontal cortex and hippocampus.

Dissociation of the physiological effects of DA and NA on target cells may be implemented by mechanisms controlling transmitter overflow and pooling. For example, DA transporter restricts the time course of dopaminergic currents in VTA while decay of noradrenergic currents in LC scales with amplitude due to lower transporter efficacy (Courtney and Ford, 2014). Such temporal variations might be a ground for functional dissociations. However, DA is not always cleared by its specific transporter; In frontal cortex and hippocampus for example, DA is primarily cleared by NA transporters (Morón et al., 2002; Guiard et al., 2008). Notably, both DA and NA can also be cleared by low affinity transporters (Duan and Wang, 2010) which can further shape their actions. Therefore, DA reuptake through shared transporters may cause a similar time course of catecholamine signaling. This can be clarified by comparing the synaptic effects of DA and NA in cortex or hippocampus and identifying transporters involved in these regions.

\section{DA AND NA INNERVATIONS AND RECEPTOR EXPRESSIONS VARY ACROSS BRAIN AREA}

The pattern of catecholamine receptor expression varies across the brain. For example, noradrenergic projections are sparse in dorsal striatum. Similarly, in the core subregion of nucleus accumbens (NAc), noradrenergic inputs are sparse while considerably dense noradrenergic fibers were found in the shell 
A

$\downarrow$ Tyrosine hydroxylase

L-DOPA

COOH

HOO $\mathrm{NH}_{2}$

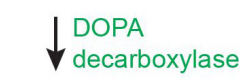

Dopamine
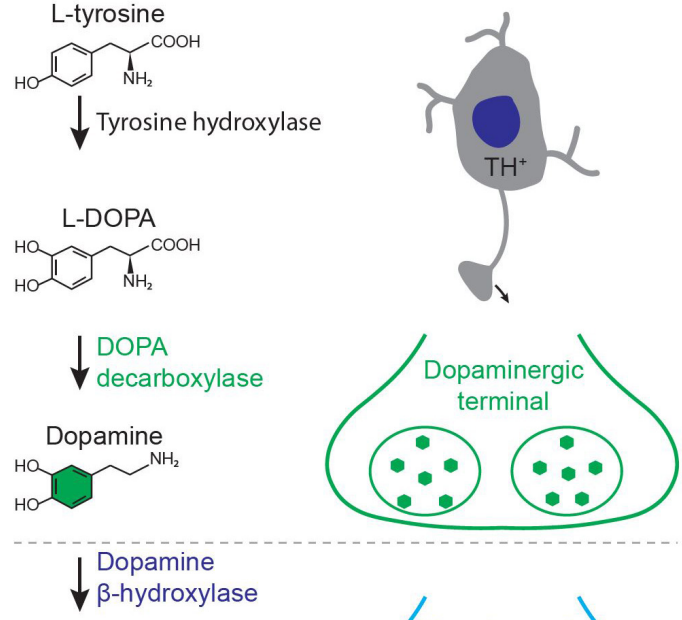

Dopaminergic terminal

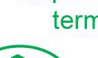

Noradrenaline
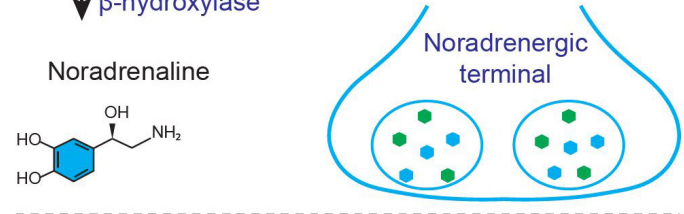

$\downarrow$ Phenylethanolamine

$\checkmark$ N-methyltransferase Adrenaline

(N)

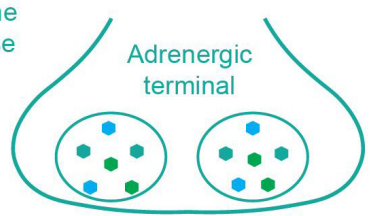

C

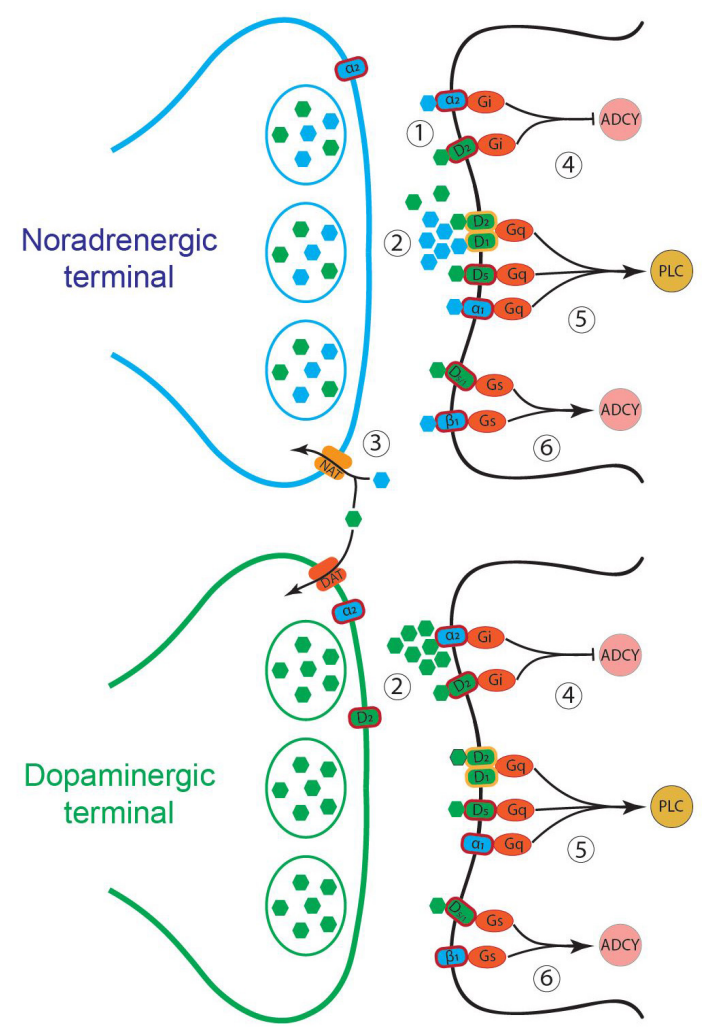

FIGURE 1 | (A) Biosynthesis of catecholamines from L-tyrosine. (B) Schematic of a tyrosine hydroxylase positive $\left(\mathrm{TH}^{+}\right)$neuron and its axonal terminals containing different combination of catecholamines, depending on the type of the neuron. (C) Noradrenergic and dopaminergic terminals. (1) Co-release of dopamine (green) and noradrenaline (blue) and their binding to specific receptors on target neurons. (2) Non-specific binding at high concentrations. (3) Non-specific transporter function. NAT, noradrenaline transporter; DAT, dopamine transporter. (4-6) Intracellular pathways shared between noradrenergic and dopaminergic receptors. ADCY, adenylyl cyclase; PLC, phospholipase C.

subregion (Berridge et al., 1997; Nomura et al., 2014). It should be mentioned, however, that the noradrenergic fibers in NAc shell originate mainly from $\alpha_{2}$ group of noradrenergic cells (Delfs et al., 1998). Consistent with the projection patterns, earlier studies showed a low NA concentration in the dorsal regions of striatum, while ventral striatum had a relatively high concentration of NA (Brownstein et al., 1974; Versteeg et al., 1976). The concentration of NA may rise due to a phasic release following novel stimuli, or tonic increase due to the changes in the brain state. Both $\beta_{1}$ and $\alpha_{2 c}$ type of adrenoceptors are highly expressed in the striatal projection neurons, dopaminergic terminals (Paschalis et al., 2009; Hara et al., 2010) and cholinergic interneurons (Pisani et al., 2003). Such dense receptor expression can make the striatal circuits sensitive to NA signaling despite overall low noradrenergic inputs. We should also consider that DA effects can also be partially mediated by $\alpha_{2}$ adrenoceptors (Cornil et al., 2008; Guiard et al., 2008). Consistently, both DA and NA can modulate the cAMP signaling pathway in the striatum (Nomura et al., 2014). Unlike basal ganglia, corticothalamic regions receive much denser input from LC (Nomura et al., 2014). Cortical regions and layers receive a relatively dense and homogeneous LC projections, while VTA projections are layer and region specific (Nomura et al., 2014). Overall, large overlaps in receptor expression and signaling pathway suggest that DA and NA may mediate similar physiological functions (Table 1). Specificity of their actions might depend on their local concentration, the timing of their release and reuptake and activity of the synaptic terminals.

\section{SIGNIFICANCE OF DA AND NA SIGNALING AND THEIR FUNCTIONAL SIMILARITIES}

Locus Coeruleus-noradrenaline system is known as the major regulator of wakefulness, vigilance, arousal, and memory formation (Aston-Jones et al., 1999; Berridge and Waterhouse, 2003; Aston-Jones and Cohen, 2005; Sara, 2009; Brown et al., 2012). LC-NA also mediates drug associated memory and reinstatement of the drug seeking behavior in addiction (Weinshenker and Schroeder, 2007; 
TABLE 1 | Similarities in physiological roles of dopamine and noradrenaline.

\begin{tabular}{|c|c|c|}
\hline Physiological role & Dopamine & Noradrenaline \\
\hline Wakefulness/ arousal/brain state & Eban-Rothschild et al., 2016 & $\begin{array}{l}\text { Aston-Jones and Cohen, 2005; Carter et al., 2010; } \\
\text { Fazlali et al., } 2016\end{array}$ \\
\hline Attention & Noudoost and Moore, 2011 & Berridge and Waterhouse, 2003; Eldar et al., 2013 \\
\hline Memory formation & Vijayraghavan et al., 2007; Shohamy and Adcock, 2010 & Berridge and Waterhouse, 2003; Sara, 2009 \\
\hline Memory consolidation & Vijayraghavan et al., 2007; Yamasaki and Takeuchi, 2017 & Berridge and Waterhouse, 2003; Sara, 2009 \\
\hline Novelty induced memory encoding & Kempadoo et al., 2016; Takeuchi et al., 2016 & Kempadoo et al., 2016; Takeuchi et al., 2016 \\
\hline Reward/ addiction & Schultz, 2001, 2007; Berke, 2018; Cox and Witten, 2019 & $\begin{array}{l}\text { Weinshenker and Schroeder, 2007; Aston-Jones } \\
\text { and Kalivas, 2008; Sara and Bouret, 2012; Bouret } \\
\text { and Richmond, } 2015\end{array}$ \\
\hline
\end{tabular}

Aston-Jones and Kalivas, 2008). Although VTA-DA system is mainly involved in action and reward processing (Schultz, 2001, 2007; Berke, 2018; Cox and Witten, 2019). It also mediates selective attention, working memory and memory consolidation in cortex and hippocampus (Vijayraghavan et al., 2007; Noudoost and Moore, 2011; Yamasaki and Takeuchi, 2017). These effects may be mediated by parallel catecholamine signaling in multiple target regions.

Convergence of the DA and NA signaling pathways suggest that they might have parallel neurophysiological effects. Indeed, from the very early intracellular studies, complex effects of both NA and DA on neuronal excitability were observed (Madison and Nicoll, 1986; Foote and Morrison, 1987; McCormick and Prince, 1988; McCormick, 1989; Zhou and Hablitz, 1999; Kröner et al., 2005). Depending on the neuronal targets and their specific receptors, DA and NA can modulate various intrinsic currents and hence excitability of the neurons (McCormick, 1989; Cathala and Paupardin-Tritsch, 1999; Seamans and Yang, 2004; Rosenkranz and Johnston, 2006; Arencibia-Albite et al., 2007). The most prominent effect of the NA is the modulation of synaptic transmission and various forms of plasticity (Harley, 1987; Mouradian et al., 1991; Sara, 2009), which are analogous to those of DA (Seamans and Yang, 2004; Tritsch and Sabatini, 2012; Froemke, 2015). In various sensory systems, both dopaminergic and noradrenergic systems were effective in remodeling the tuning properties of the cortical neurons (Bao et al., 2001; Manunta and Edeline, 2004; Edeline et al., 2011; Martins and Froemke, 2015; McBurney-Lin et al., 2019; Waterhouse and Navarra, 2019). Notably, both systems also contribute to the maintenance and transitions of global brain states, wakefulness, arousal, attention, and memory consolidation (Berridge, 2008; Carter et al., 2010; Lee and Dan, 2012; Eban-Rothschild et al., 2016; Fazlali et al., 2016; Sara, 2017; Schicknick et al., 2019). Reward or punishment related stimuli appear to activate catecholamine producing neurons in both LC and VTA (Bouret and Sara, 2004; Sara, 2009; Sara and Bouret, 2012; Bouret and Richmond, 2015). Furthermore, adrenergic and noradrenergic projections to VTA (Mejías-Aponte et al., 2009) may serve to rapidly broadcast behaviorally relevant signals.

In multiple brain regions the activation of adrenergic receptors enhances long term potentiation, working memory, memory consolidation and retrieval (Sara, 2009). These functions are similar to dopaminergic effects on memory processes
(Shohamy and Adcock, 2010). It is assumed that the reward related memory consolidation and learning is mediated through VTA-DA system (Schultz, 2001; Berke, 2018). However, LC neuronal activity is also correlated with reward expectation (Bouret and Richmond, 2015). In parallel with VTA-DA system, dopamine release from dense LC terminals in prefrontal cortex and hippocampus may also serve as a strong reward associated signal to facilitate learning and novelty induced memory encoding (Kempadoo et al., 2016; Takeuchi et al., 2016). Overall DA and NA appear to have parallel effects on learning, brain state and reward processing.

\section{DA AND NA CO-RELEASE FROM THE LOCUS COERULEUS}

Locus Coeruleus has long been identified as a noradrenergic center, where majority of the cells produce noradrenaline from dopamine by expressing dopamine-beta-hydroxylase (Figure 1A). A long-standing challenge, however, was to establish whether these cells store and release DA as a cotransmitter together with NA (Figures 1B,C). The first evidence for DA-NA co-release came from measurements of the DA and NA concentrations in the cortical area following psychoactive drugs or LC pharmacological stimulation (Kawahara et al., 2001; Devoto et al., 2005a, 2006). These studies showed that noradrenergic stimulation/suppression causes a parallel change in concentration of both DA and NA in cortical regions. This was often interpreted as a direct or indirect interaction between VTA and LC projections in the cortical area (Kawahara et al., 2001; Chandler et al., 2014; Xing et al., 2016). Such interactions can be due to the direct projections from noradrenergic nuclei to VTA (Mejías-Aponte et al., 2009), control of DA release from dopaminergic terminals via adrenoceptors (Yavich et al., 1997; Ihalainen and Tanila, 2002) and/or competition of NA and DA for the same transporter (Morón et al., 2002; Yamamoto and Novotney, 2002; Borgkvist et al., 2011). Alternatively, it was also hypothesized that DA can be released from LC terminals as a co-transmitter (Devoto et al., 2006).

Earlier pharmacological studies provided strong evidence for DA-NA co-transmission hypothesis; (1) It was shown that the DA levels in parietal, occipital, and cerebellar cortices - which are poorly innervated by DA fibers - were as high as densely 
innervated medial prefrontal cortex (Devoto et al., 2001). (2) Dopamine receptor antagonists which were known to enhance DA concentration in striatum, were not as effective as adrenergic agonists and antagonists in modifying DA levels in cortex (Kuroki et al., 1999; Devoto et al., 2001, 2003b, 2004). (3) Chemical and electrical alterations of the LC activity significantly modulated the NA and DA concentrations in cortical regions (Kawahara et al., 2001; Devoto et al., 2003a, 2005a,b; Masana et al., 2011). (4) Electrical stimulation of the LC did not change DA concentration in striatum but significantly increased NA level in this region (Devoto et al., 2005a,b). (5) Selective lesion studies and specific disruption of catecholamine production in VTA and LC confirmed that noradrenergic terminals are the main source of dopamine in cortical regions (Pozzi et al., 1994; Devoto et al., 2008, 2015, 2019; Smith and Greene, 2012). Moreover, several medications for neuropsychiatric conditions increase both DA and NA in the brain (Devoto et al., 2006).

Novel genetic and optogenetic techniques make it possible to study the function of neuromodulator nuclei with greater specificity (Carter et al., 2010; Eban-Rothschild et al., 2016). Using these methods, recent studies dissected VTA and LC projections in hippocampus and found that dopamine release from dense LC projections is the primary cause of learning and memory in certain tasks (Kempadoo et al., 2016; Takeuchi et al., 2016; McNamara and Dupret, 2017). Optogenetic stimulation of LC terminals in hippocampus enhanced DA together with NA and specific LC lesion reduced both neurochemicals (Kempadoo et al., 2016). More importantly, these studies for the first time revealed a strong causal link between dopamine release from LC projections and performance in certain learning and memory tasks. Kandle and colleagues showed that photo-stimulation of LC projections in dorsal hippocampus improved mice performance in spatial learning and memory tasks (Kempadoo et al., 2016). At the same time, Morris and colleagues found that LC dopaminergic activity in the hippocampus is necessary for novelty associated memory formation (Takeuchi et al., 2016). Surprisingly, noradrenergic blockade in hippocampus had no effect on either spatial memory or novelty associated memory enhancement (Kempadoo et al., 2016; Takeuchi et al., 2016), despite earlier studies showing beta-adrenergic dependent memory-encoding and plasticity (Straube et al., 2003; Lemon et al., 2009). Overall these studies confirmed the DA-NA cotransmission and the significant role of LC-DA in spatial memory encoding and novelty induced memory consolidation. Whether DA-NA release from LC contributes to distinct memory processes from VTA-DA remains elusive (Yamasaki and Takeuchi, 2017; Duszkiewicz et al., 2019).

\section{REFERENCES}

Agnati, L. F., Zoli, M., Strömberg, I., and Fuxe, K. (1995). Intercellular communication in the brain: wiring versus volume transmission. Neuroscience 69, 711-726. doi: 10.1016/0306-4522(95)00308-6

Arencibia-Albite, F., Paladini, C., Williams, J. T., and Jiménez-Rivera, C. A. (2007). Noradrenergic modulation of the hyperpolarization-activated cation current (Ih) in dopamine neurons of the ventral tegmental area. Neuroscience 149, 303-314. doi: 10.1016/j.neuroscience.2007.08.009

\section{CONCLUDING REMARKS AND FUTURE DIRECTIONS}

An overview of the studies on dopamine and noradrenaline signaling and function in the CNS suggests that these systems may act in parallel and overlapping manner. Here we provided an integrative approach to support this view. Highly overlapping functions of catecholamines raise important questions; Does LC release DA throughout the brain? What are the functional interactions of LC and VTA? How does the distribution of receptors and transporters of catecholamines determine their specific function? Is ratio of DA/NA important and how can it change? Recent developments of the synthetic and genetically encoded catecholamine sensors (Patriarchi et al., 2018; Sun et al., 2018; Beyene et al., 2019; Feng et al., 2019) together with well-established optogenetic and twophoton imaging techniques make it possible to dissect the role of these neuromodulators in brain computations. Superior spatiotemporal resolution of these sensors makes it possible to examine local/global signaling, volume transmission, corelease and interactions of catecholamines. DA and NA are involved in major brain computations such as sensory processing, motor planning, plasticity, and memory encoding. They are also crucial in mood maintenance, motivation, and concentration.

Future studies should attempt to decode behaviorally relevant signals in LC and VTA and compare the modulatory effects of LC-DA, LC-NA, and VTA-DA in cortex, hippocampus, and ventral striatum. Adrenergic and noradrenergic nuclei other than LC also require a fresh attention in this regard. A better understanding of these systems would facilitate the advent of more effective therapeutics for a range of psychiatric conditions, such as depression (Nutt et al., 2007; Hare et al., 2019), schizophrenia (Winograd-Gurvich et al., 2006; Howes et al., 2017; Matthews et al., 2018), ADHD (Levy, 2009; Tripp and Wickens, 2009), PTSD (Hendrickson and Raskind, 2016), and addiction (Weinshenker and Schroeder, 2007). It is not clear how different neuromodulatory systems are disrupted in these disorders. Research on the overlapping functions of the neuromodulators can provide a new insight into the mechanisms of neuropsychiatric disorders.

\section{AUTHOR CONTRIBUTIONS}

YR-S and ZF equally contributed to the conception and writing of the manuscript.

Arnsten, A. F., Wang, M. J., and Paspalas, C. D. (2012). Neuromodulation of thought: flexibilities and vulnerabilities in prefrontal cortical network synapses. Neuron 76, 223-239. doi: 10.1016/j.neuron.2012.08.038

Aston-Jones, G., and Cohen, J. D. (2005). An integrative theory of locus coeruleusnorepinephrine function: adaptive gain and optimal performance. Annu. Rev. Neurosci. 28, 403-450. doi: 10.1146/annurev.neuro.28.061604.135709

Aston-Jones, G., and Kalivas, P. W. (2008). Brain norepinephrine rediscovered in addiction research. Biol. Psychiatry 63, 1005-1006. doi: 10.1016/j.biopsych. 2008.03.016 
Aston-Jones, G., Rajkowski, J., and Cohen, J. (1999). Role of locus coeruleus in attention and behavioral flexibility. Biol. Psychiatry 46, 1309-1320. doi: 10 . 1016/s0006-3223(99)00140-7

Bao, S., Chan, V. T., and Merzenich, M. M. (2001). Cortical remodelling induced by activity of ventral tegmental dopamine neurons. Nature 412, 79-83. doi: $10.1038 / 35083586$

Beaulieu, J.-M., and Gainetdinov, R. R. (2011). The physiology, signaling, and pharmacology of dopamine receptors. Pharmacol. Rev. 63, 182-217. doi: 10. $1124 /$ pr.110.002642

Berke, J. D. (2018). What does dopamine mean? Nat. Neurosci. 21, 787-793. doi: 10.1038/s41593-018-0152-y

Berridge, C. W. (2008). Noradrenergic modulation of arousal. Brain Res. Rev. 58, 1-17. doi: 10.1016/j.brainresrev.2007.10.013

Berridge, C. W., Stratford, T. L., Foote, S. L., and Kelley, A. E. (1997). Distribution of dopamine beta-hydroxylase-like immunoreactive fibers within the shell subregion of the nucleus accumbens. Synapse 27, 230-241. doi: 10.1002/(sici) 1098-2396(199711)27:3<230::aid-syn8>3.0.co;2-e

Berridge, C. W., and Waterhouse, B. D. (2003). The locus coeruleus-noradrenergic system: modulation of behavioral state and state-dependent cognitive processes. Brain Res. Brain Res. Rev. 42, 33-84. doi: 10.1016/S0165-0173(03)00143-7

Beyene, A. G., Delevich, K., Del Bonis-O’Donnell, J. T., Piekarski, D. J., Lin, W. C., Thomas, A. W., et al. (2019). Imaging striatal dopamine release using a nongenetically encoded near infrared fluorescent catecholamine nanosensor. Sci. Adv. 5:eaaw3108. doi: 10.1126/sciadv.aaw3108

Borgkvist, A., Malmlöf, T., Feltmann, K., Lindskog, M., and Schilström, B. (2011). Dopamine in the hippocampus is cleared by the norepinephrine transporter. Int. J. Neuropsychopharmacol. 15, 1-10. doi: 10.1017/S146114571100 0812

Bouret, S., and Richmond, B. J. (2015). Sensitivity of locus ceruleus neurons to reward value for goal-directed actions. J. Neurosci. 35, 4005-4014. doi: 10.1523/ JNEUROSCI.4553-14.2015

Bouret, S., and Sara, S. J. (2004). Reward expectation, orientation of attention and locus coeruleus-medial frontal cortex interplay during learning. Eur. J. Neurosci. 20, 791-802. doi: 10.1111/j.1460-9568.2004.03526.x

Brown, R. E., Basheer, R., McKenna, J. T., Strecker, R. E., and McCarley, R. W. (2012). Control of sleep and wakefulness. Physiol. Rev. 92, 1087-1187. doi: 10.1152/physrev.00032.2011

Brownstein, M., Saavedra, J. M., and Palkovits, M. (1974). Norepinephrine and dopamine in the limbic system of the rat. Brain Res. 79, 431-436. doi: 10.1016/ 0006-8993(74)90440-5

Carter, M. E., Yizhar, O., Chikahisa, S., Nguyen, H., Adamantidis, A., Nishino, S., et al. (2010). Tuning arousal with optogenetic modulation of locus coeruleus neurons. Nat. Neurosci. 13, 1526-1533. doi: 10.1038/nn.2682

Cathala, L., and Paupardin-Tritsch, D. (1999). Effect of catecholamines on the hyperpolarization-activated cationic $\mathrm{I} h$ and the inwardly rectifying potassium I Kir currents in the rat substantia nigra pars compacta. Eur. J. Neurosci. 11, 398-406. doi: 10.1046/j.1460-9568.1999.00452.x

Chandler, D. J., Waterhouse, B. D., and Gao, W.-J. (2014). New perspectives on catecholaminergic regulation of executive circuits: evidence for independent modulation of prefrontal functions by midbrain dopaminergic and noradrenergic neurons. Front. Neural Circuits 8:53. doi: 10.3389/fncir.2014.00053

Cornil, C. A., Castelino, C. B., and Ball, G. F. (2008). Dopamine binds to $\alpha 2$ adrenergic receptors in the song control system of zebra finches (Taeniopygia guttata). J. Chem. Neuroanat. 35, 202-215. doi: 10.1016/J.JCHEMNEU.2007. 10.004

Courtney, N. A., and Ford, C. P. (2014). The timing of dopamine- and noradrenaline-mediated transmission reflects underlying differences in the extent of spillover and pooling. J. Neurosci. 34, 7645-7656. doi: 10.1523/ JNEUROSCI.0166-14.2014

Cox, J., and Witten, I. B. (2019). Striatal circuits for reward learning and decisionmaking. Nat. Rev. Neurosci. 20, 482-494. doi: 10.1038/s41583-019-0189-2

Dayan, P. (2012). Twenty-five lessons from computational neuromodulation. Neuron 76, 240-256. doi: 10.1016/j.neuron.2012.09.027

Delfs, J. M., Zhu, Y., Druhan, J. P., and Aston-Jones, G. S. (1998). Origin of noradrenergic afferents to the shell subregion of the nucleus accumbens: anterograde and retrograde tract-tracing studies in the rat. Brain Res. 806, 127-140. doi: 10.1016/s0006-8993(98)00672-6
Devoto, P., Flore, G., and Brodie, B. B. (2006). On the origin of cortical dopamine: is it a co-transmitter in noradrenergic neurons? Curr. Neuropharmacol. 4, 115-125. doi: 10.2174/157015906776359559

Devoto, P., Flore, G., Longu, G., Pira, L., and Gessa, G. L. (2003a). Origin of extracellular dopamine from dopamine and noradrenaline neurons in the medial prefrontal and occipital cortex. Synapse 50, 200-205. doi: 10.1002/syn. 10264

Devoto, P., Flore, G., Vacca, G., Pira, L., Arca, A., Casu, M. A., et al. (2003b). Co-release of noradrenaline and dopamine from noradrenergic neurons in the cerebral cortex induced by clozapine, the prototype atypical antipsychotic. Psychopharmacology 167, 79-84. doi: 10.1007/s00213-002-1381-y

Devoto, P., Flore, G., Pani, L., and Gessa, G. L. (2001). Evidence for co-release of noradrenaline and dopamine from noradrenergic neurons in the cerebral cortex. Mol. Psychiatry 6, 657-664. doi: 10.1038/sj.mp.4000904

Devoto, P., Flore, G., Pira, L., Longu, G., and Gessa, G. L. (2004). Alpha2adrenoceptor mediated co-release of dopamine and noradrenaline from noradrenergic neurons in the cerebral cortex. J. Neurochem. 88, 1003-1009. doi: 10.1046/j.1471-4159.2003.02239.x

Devoto, P., Flore, G., Saba, P., Castelli, M. P., Piras, A. P., Luesu, W., et al. (2008). 6-Hydroxydopamine lesion in the ventral tegmental area fails to reduce extracellular dopamine in the cerebral cortex. J. Neurosci. Res. 86, 1647-1658. doi: 10.1002/jnr.21611

Devoto, P., Flore, G., Saba, P., Fà, M., and Gessa, G. L. (2005a). Co-release of noradrenaline and dopamine in the cerebral cortex elicited by single train and repeated train stimulation of the locus coeruleus. BMC Neurosci. 6:31. doi: 10.1186/1471-2202-6-31

Devoto, P., Flore, G., Saba, P., Fà, M., and Gessa, G. L. (2005b). Stimulation of the locus coeruleus elicits noradrenaline and dopamine release in the medial prefrontal and parietal cortex. J. Neurochem. 92, 368-374. doi: 10.1111/j.14714159.2004.02866.x

Devoto, P., Flore, G., Saba, P., Frau, R., and Gessa, G. L. (2015). Selective inhibition of dopamine-beta-hydroxylase enhances dopamine release from noradrenergic terminals in the medial prefrontal cortex. Brain Behav. 5:e00393. doi: 10.1002/ brb3.393

Devoto, P., Flore, G., Saba, P., Scheggi, S., Mulas, G., Gambarana, C., et al. (2019). Noradrenergic terminals are the primary source of $\alpha 2$-adrenoceptor mediated dopamine release in the medial prefrontal cortex. Prog. Neuro Psychopharmacol. Biol. Psychiatry 90, 97-103. doi: 10.1016/J.PNPBP.2018.11.015

Duan, H., and Wang, J. (2010). Selective transport of monoamine neurotransmitters by human plasma membrane monoamine transporter and organic cation transporter 3. J. Pharmacol. Exp. Ther. 335, 743-753. doi: 10.1124/jpet.110.170142

Duszkiewicz, A. J., McNamara, C. G., Takeuchi, T., and Genzel, L. (2019). Novelty and dopaminergic modulation of memory persistence: a tale of two systems. Trends Neurosci. 42, 102-114. doi: 10.1016/j.tins.2018.10.002

Eban-Rothschild, A., Rothschild, G., Giardino, W. J., Jones, J. R., and de Lecea, L. (2016). VTA dopaminergic neurons regulate ethologically relevant sleep-wake behaviors. Nat. Neurosci. 19, 1356-1366. doi: 10.1038/nn.4377

Edeline, J.-M., Manunta, Y., and Hennevin, E. (2011). Induction of selective plasticity in the frequency tuning of auditory cortex and auditory thalamus neurons by locus coeruleus stimulation. Hear. Res. 274, 75-84. doi: 10.1016/j. heares.2010.08.005

Eldar, E., Cohen, J. D., and Niv, Y. (2013). The effects of neural gain on attention and learning. Nat. Neurosci. 16, 1146-1153. doi: 10.1038/nn.3428

El Mansari, M., Guiard, B. P., Chernoloz, O., Ghanbari, R., Katz, N., and Blier, P. (2010). Relevance of norepinephrine-dopamine interactions in the treatment of major depressive disorder. CNS Neurosci. Ther. 16, e1-e17. doi: 10.1111/j.17555949.2010.00146.x

Fazlali, Z., Ranjbar-Slamloo, Y., Adibi, M., and Arabzadeh, E. (2016). Correlation between locus coeruleus activity and cortical state : implications for sensory coding in rat barrel cortex. Front. Neural Circuits 10:e14. doi: 10.3389/fncir. 2016.00014

Feng, J., Zhang, C., Lischinsky, J. E., Jing, M., Zhou, J., Wang, H., et al. (2019). A genetically encoded fluorescent sensor for rapid and specific in vivo detection of norepinephrine. Neuron 102, 745.e8-761.e8. doi: 10.1016/j.neuron.2019.02.037

Foote, S. L., and Morrison, J. H. (1987). Extrathalamic modulation of cortical function. Annu. Rev. Neurosci. 10, 67-95. doi: 10.1146/annurev.ne.10.030187. 000435 
Froemke, R. C. (2015). Plasticity of cortical excitatory-inhibitory balance. Annu. Rev. Neurosci. 38, 195-219. doi: 10.1146/annurev-neuro-071714-03 4002

Fuxe, K., Dahlström, A. B., Jonsson, G., Marcellino, D., Guescini, M., Dam, M., et al. (2010). The discovery of central monoamine neurons gave volume transmission to the wired brain. Prog. Neurobiol. 90, 82-100. doi: 10.1016/J. PNEUROBIO.2009.10.012

Guiard, B. P., El Mansari, M., and Blier, P. (2008). Cross-Talk between dopaminergic and noradrenergic systems in the rat ventral tegmental area. locus ceruleus, and dorsal Hippocampus. Mol. Pharmacol. 74, 1463-1475. doi: 10.1124/mol.108.048033

Hara, M., Fukui, R., Hieda, E., Kuroiwa, M., Bateup, H. S., Kano, T., et al. (2010). Role of adrenoceptors in the regulation of dopamine/DARPP-32 signaling in neostriatal neurons. J. Neurochem. 113, 1046-1059. doi: 10.1111/j.1471-4159. 2010.06668.x

Hare, B. D., Shinohara, R., Liu, R. J., Pothula, S., DiLeone, R. J., and Duman, R. S. (2019). Optogenetic stimulation of medial prefrontal cortex Drd1 neurons produces rapid and long-lasting antidepressant effects. Nat. Commun. 10:223. doi: 10.1038/s41467-018-08168-9

Harley, C. W. (1987). A role for norepinephrine in arousal, emotion and learning : limbic modulation by norepinephrine and the kety hypothesis. Prog. Neuro Psychopharmacol. Biol. Psychiatry 11, 419-458. doi: 10.1016/0278-5846(87) 90015-7

Hendrickson, R. C., and Raskind, M. A. (2016). Noradrenergic dysregulation in the pathophysiology of PTSD. Exp. Neurol. 284, 181-195. doi: 10.1016/J. EXPNEUROL.2016.05.014

Howes, O. D., McCutcheon, R., Owen, M. J., and Murray, R. M. (2017). The role of genes, stress, and dopamine in the development of schizophrenia. Biol. Psychiatry 81, 9-20. doi: 10.1016/J.BIOPSYCH.2016.07.014

Ihalainen, J. A., and Tanila, H. (2002). In vivo regulation of dopamine and noradrenaline release by $\alpha 2 \mathrm{~A}$-adrenoceptors in the mouse prefrontal cortex. Eur. J. Neurosci. 15, 1789-1794. doi: 10.1046/j.1460-9568.2002. 02014.x

Kawahara, H., Kawahara, Y., and Westerink, B. H. C. (2001). The noradrenalinedopamine interaction in the rat medial prefrontal cortex studied by multi-probe microdialysis. Eur. J. Pharmacol. 418, 177-186. doi: 10.1016/S0014-2999(01) 00863-9

Kempadoo, K. A., Mosharov, E. V., Choi, S. J., Sulzer, D., and Kandel, E. R. (2016). Dopamine release from the locus coeruleus to the dorsal hippocampus promotes spatial learning and memory. Proc. Natl. Acad. Sci.U.S.A. 113, 1483514840. doi: 10.1073/pnas.1616515114

Kröner, S., Rosenkranz, J. A., Grace, A. A., and Barrionuevo, G. (2005). Dopamine modulates excitability of basolateral amygdala neurons in vitro. J. Neurophysiol. 93, 1598-1610. doi: 10.1152/jn.00843.2004

Kuroki, T., Meltzer, H. Y., and Ichikawa, J. (1999). Effects of antipsychotic drugs on extracellular dopamine levels in rat medial prefrontal cortex and nucleus accumbens. J. Pharmacol. Exp. Ther. 266, 1374-1384.

Lee, S.-H., and Dan, Y. (2012). Neuromodulation of brain states. Neuron 76, 209-222. doi: 10.1016/j.neuron.2012.09.012

Lemon, N., Aydin-Abidin, S., Funke, K., and Manahan-Vaughan, D. (2009). Locus coeruleus activation facilitates memory encoding and induces hippocampal ltd that depends on -adrenergic receptor activation. Cereb. Cortex 19, 2827-2837. doi: $10.1093 /$ cercor/bhp065

Levy, F. (2009). Dopamine vs noradrenaline: inverted-U effects and ADHD theories. Aust. N. Z. J. Psychiatry 43, 101-108. doi: 10.1080/00048670802607238

Madison, D. V., and Nicoll, R. A. (1986). Actions of noradrenaline recorded intracellularly in rat hippocampal CA1 pyramidal neurones, in vitro. J. Physiol. 372, 221-244. doi: 10.1113/jphysiol.1986.sp016006

Manunta, Y., and Edeline, J.-M. (2004). Noradrenergic induction of selective plasticity in the frequency tuning of auditory cortex neurons. J. Neurophysiol. 92, 1445-1463. doi: 10.1152/jn.00079.2004

Martins, A. R. O., and Froemke, R. C. (2015). Coordinated forms of noradrenergic plasticity in the locus coeruleus and primary auditory cortex. Nat. Neurosci. 18, 1483-1492. doi: 10.1038/nn.4090

Masana, M., Bortolozzi, A., and Artigas, F. (2011). Selective enhacement of mesocortical dopaminergic transmission by noradrenergic drugs: therapeutic opportunities in schizophrenia. Int. J. Neuropsychopharmacol. 14, 53-68. doi: $10.1017 /$ S1461145710000908
Matthews, P. R. L., Horder, J., and Pearce, M. (2018). Selective noradrenaline reuptake inhibitors for schizophrenia. Cochrane Database Syst. Rev. 2018:CD010219. doi: 10.1002/14651858.CD010219.pub2

McBurney-Lin, J., Lu, J., Zuo, Y., and Yang, H. (2019). Locus coeruleusnorepinephrine modulation of sensory processing and perception: a focused review. Neurosci. Biobehav. Rev. 105, 190-199. doi: 10.1016/J.NEUBIOREV. 2019.06.009

McCormick, D. A. (1989). Cholinergic and noradrenergic modulation of thalamocortical processing. Trends Neurosci. 12, 215-221. doi: 10.1016/01662236(89)90125-2

McCormick, D. A., and Prince, D. A. (1988). Noradrenergic modulation of firing pattern in guinea pig and cat thalamic neurons, in vitro. J. Neurophysiol. 59, 978-996. doi: 10.1152/jn.1988.59.3.978

McNamara, C. G., and Dupret, D. (2017). Two sources of dopamine for the hippocampus. Trends Neurosci. 40, 383-384. doi: 10.1016/j.tins.2017.05.005

Mejías-Aponte, C. A., Drouin, C., and Aston-Jones, G. (2009). Adrenergic and noradrenergic innervation of the midbrain ventral tegmental area and retrorubral field: prominent inputs from medullary homeostatic centers. J. Neurosci. 29, 3613-3626. doi: 10.1523/JNEUROSCI.4632-08.2009

Morón, J. A., Brockington, A., Wise, R. A., Rocha, B. A., and Hope, B. T. (2002). Dopamine uptake through the norepinephrine transporter in brain regions with low levels of the dopamine transporter: evidence from knock-out mouse lines. J. Neurosci. 22, 389-395. doi: 10.1523/JNEUROSCI.22-02-00389.2002

Mouradian, R. D., Sessler, F. M., and Waterhouse, B. D. (1991). Noradrenergic potentiation of excitatory transmitter action in cerebrocortical slices: evidence for mediation by an $\alpha 1$ receptor-linked second messenger pathway. Brain Res. 546, 83-95. doi: 10.1016/0006-8993(91)91162-T

Nasse, J. S., and Travers, J. B. (2014). Adrenoreceptor modulation of oromotor pathways in the rat medulla. J. Neurophysiol. 112, 580-593. doi: 10.1152/jn. 00091.2014

Nomura, S., Bouhadana, M., Morel, C., Faure, P., Cauli, B., Lambolez, B., et al. (2014). Noradrenalin and dopamine receptors both control cAMP-PKA signaling throughout the cerebral cortex. Front. Cell. Neurosci. 8:247. doi: 10. 3389/fncel.2014.00247

Noudoost, B., and Moore, T. (2011). The role of neuromodulators in selective attention. Trends Cogn. Sci. 15, 585-591. doi: 10.1016/J.TICS.2011.10.006

Nutt, D., Demyttenaere Gasthuisberg, K. U., Psychiatry, G., Zoltan Janka, B., Aarre, T., Bourin, M., et al. (2007). The other face of depression, reduced positive affect: the role of catecholamines in causation and cure. J. Psychopharmacol. 21, 461-471. doi: 10.1177/0269881106069938

Paschalis, A., Churchill, L., Marina, N., Kasymov, V., Gourine, A., and Ackland, G. (2009). $\beta 1$-Adrenoceptor distribution in the rat brain: an immunohistochemical study. Neurosci. Lett. 458, 84-88. doi: 10.1016/j.neulet.2009.04.023

Patriarchi, T., Cho, J. R., Merten, K., Howe, M. W., Marley, A., Xiong, W. H., et al. (2018). Ultrafast neuronal imaging of dopamine dynamics with designed genetically encoded sensors. Science 360:eaat4422. doi: 10.1126/science.aat 4422

Pisani, A., Bonsi, P., Centonze, D., Martorana, A., Fusco, F., Sancesario, G., et al. (2003). Activation of betal-adrenoceptors excites striatal cholinergic interneurons through a cAMP-dependent, protein kinase-independent pathway. J. Neurosci. 23, 5272-5282. doi: 10.1523/JNEUROSCI.23-12-05272. 2003

Poulin, J.-F., Caronia, G., Hofer, C., Cui, Q., Helm, B., Ramakrishnan, C., et al. (2018). Mapping projections of molecularly defined dopamine neuron subtypes using intersectional genetic approaches. Nat. Neurosci. 21, 1260-1271. doi: 10. 1038/s41593-018-0203-4

Pozzi, L., Invernizzi, R., Cervo, L., Vallebuona, F., and Samanin, R. (1994). Evidence that extracellular concentrations of dopamine are regulated by noradrenergic neurons in the frontal cortex of rats. J. Neurochem. 63, 195-200. doi: 10.1046/j. 1471-4159.1994.63010195.x

Reiner, A., and Levitz, J. (2018). Glutamatergic signaling in the central nervous system: ionotropic and metabotropic receptors in concert. Neuron 98, 10801098. doi: 10.1016/j.neuron.2018.05.018

Robertson, S. D., Plummer, N. W., de Marchena, J., and Jensen, P. (2013). Developmental origins of central norepinephrine neuron diversity. Nat. Neurosci. 16, 1016-1023. doi: 10.1038/nn.3458

Rosenkranz, J. A., and Johnston, D. (2006). Dopaminergic regulation of neuronal excitability through modulation of IH in layer V entorhinal cortex. J. Neurosci. 23, 2686-2695. doi: 10.1523/jneurosci.4333-05.2006 
Sara, S. J. (2009). The locus coeruleus and noradrenergic modulation of cognition. Nat. Rev. Neurosci. 10, 211-223. doi: 10.1038/nrn2573

Sara, S. J. (2017). Sleep to remember. J. Neurosci. 37, 457-463. doi: 10.1523/ JNEUROSCI.0297-16.2017

Sara, S. J., and Bouret, S. (2012). Orienting and reorienting: the locus coeruleus mediates cognition through arousal. Neuron 76, 130-141. doi: 10.1016/j. neuron.2012.09.011

Schicknick, H., Henschke, J. U., Budinger, E., Ohl, F. W., Gundelfinger, E. D., and Tischmeyer, W. (2019). $\beta$-adrenergic modulation of discrimination learning and memory in the auditory cortex. Eur. J. Neurosci. 50, 3141-3163. doi: 10. 1111/ejn. 14480

Schmidt, K. T., and Weinshenker, D. (2014). Adrenaline rush: the role of adrenergic receptors in stimulant-induced behaviors. Mol. Pharmacol. 85, 640-650. doi: 10.1124/mol.113.090118

Schultz, W. (2001). Reward signaling by dopamine neurons. Neuroscientist 7, 293-302. doi: 10.1177/107385840100700406

Schultz, W. (2007). Multiple dopamine functions at different time courses. Annu. Rev. Neurosci. 30, 259-288. doi: 10.1146/annurev.neuro.28.061604.135722

Seamans, J. K., and Yang, C. R. (2004). The principal features and mechanisms of dopamine modulation in the prefrontal cortex. Prog. Neurobiol. 74, 1-58. doi: 10.1016/J.PNEUROBIO.2004.05.006

Shohamy, D., and Adcock, R. A. (2010). Dopamine and adaptive memory. Trends Cogn. Sci. 14, 464-472. doi: 10.1016/J.TICS.2010.08.002

Smith, C. C., and Greene, R. W. (2012). CNS dopamine transmission mediated by noradrenergic innervation. J. Neurosci. 32, 6072-6080. doi: 10.1523/ JNEUROSCI.6486-11.2012

Straube, T., Korz, V., Balschun, D., and Uta Frey, J. (2003). Requirement of $\beta$ adrenergic receptor activation and protein synthesis for LTP-reinforcement by novelty in rat dentate gyrus. J. Physiol. 552, 953-960. doi: 10.1113/jphysiol.2003. 049452

Sulzer, D., Cragg, S. J., and Rice, M. E. (2016). Striatal dopamine neurotransmission: regulation of release and uptake. Basal Ganglia 6 123-148. doi: 10.1016/J.BAGA.2016.02.001

Sun, F., Zeng, J., Jing, M., Zhou, J., Feng, J., Owen, S. F., et al. (2018). A Genetically Encoded Fluorescent Sensor Enables Rapid and Specific Detection of Dopamine in Flies, Fish, and Mice. Cell 174, 481.e19-496.e19. doi: 10.1016/J.CELL.2018. 06.042

Taber, K. H., and Hurley, R. A. (2014). Volume transmission in the brain: beyond the synapse. J. Neuropsychiatry Clin. Neurosci. 26, 1-4. doi: 10.1176/appi. neuropsych.13110351

Takeuchi, T., Duszkiewicz, A. J., Sonneborn, A., Spooner, P. A., Yamasaki, M., Watanabe, M., et al. (2016). Locus coeruleus and dopaminergic consolidation of everyday memory. Nature 537, 357-362. doi: 10.1038/nature19325

Tripp, G., and Wickens, J. R. (2009). Neurobiology of ADHD. Neuropharmacology 57, 579-589. doi: 10.1016/J.NEUROPHARM.2009.07.026

Tritsch, N. X., and Sabatini, B. L. (2012). Dopaminergic modulation of synaptic transmission in cortex and striatum. Neuron 76, 33-50. doi: 10.1016/J. NEURON.2012.09.023
Vaaga, C. E., Borisovska, M., and Westbrook, G. L. (2014). Dual-transmitter neurons: functional implications of co-release and co-transmission. Curr. Opin. Neurobiol. 29, 25-32. doi: 10.1016/j.conb.2014.04.010

Versteeg, D. H. G., Van der Gugten, J., De Jong, W., and Palkovits, M. (1976). Regional concentrations of noradrenaline and dopamine in rat brain. Brain Res. 113, 563-574. doi: 10.1016/0006-8993(76)90057-3

Vijayraghavan, S., Wang, M., Birnbaum, S. G., Williams, G. V., and Arnsten, A. F. T. (2007). Inverted-U dopamine D1 receptor actions on prefrontal neurons engaged in working memory. Nat. Neurosci. 10, 376-384. doi: 10.1038/ nn 1846

Waterhouse, B. D., and Navarra, R. L. (2019). The locus coeruleus-norepinephrine system and sensory signal processing: a historical review and current perspectives. Brain Res. 1709, 1-15. doi: 10.1016/J.BRAINRES.2018. 08.032

Weinshenker, D., and Schroeder, J. P. (2007). There and back again: a tale of norepinephrine and drug addiction. Neuropsychopharmacology 32, 1433-1451. doi: 10.1038/sj.npp.1301263

Winograd-Gurvich, C., Fitzgerald, P. B., Georgiou-Karistianis, N., Bradshaw, J. L., and White, O. B. (2006). Negative symptoms: a review of schizophrenia, melancholic depression and Parkinson's disease. Brain Res. Bull. 70, 312-321. doi: 10.1016/J.BRAINRESBULL.2006.06.007

Xing, B., Li, Y.-C., and Gao, W.-J. (2016). Norepinephrine versus dopamine and their interaction in modulating synaptic function in the prefrontal cortex. Brain Res. 1641, 217-233. doi: 10.1016/J.BRAINRES.2016.01.005

Yamamoto, B. K., and Novotney, S. (2002). Regulation of extracellular dopamine by the norepinephrine transporter. J. Neurochem. 71, 274-280. doi: 10.1046/j. 1471-4159.1998.71010274.x

Yamasaki, M., and Takeuchi, T. (2017). Locus coeruleus and dopamine-dependent memory consolidation. Neural Plast. 2017, 1-15. doi: 10.1155/2017/860 2690

Yavich, L., Lappalainen, R., Sirviö, J., Haapalinna, A., and MacDonald, E. (1997). a2-Adrenergic control of dopamine overflow and metabolism in mouse striatum. Eur. J. Pharmacol. 339, 113-119. doi: 10.1016/S0014-2999(97)01 375-7

Zhou, F.-M., and Hablitz, J. J. (1999). Dopamine modulation of membrane and synaptic properties of interneurons in rat cerebral cortex. J. Neurophysiol. 81, 967-976. doi: 10.1152/jn.1999.81.3.967

Conflict of Interest: The authors declare that the research was conducted in the absence of any commercial or financial relationships that could be construed as a potential conflict of interest.

Copyright (C) 2020 Ranjbar-Slamloo and Fazlali. This is an open-access article distributed under the terms of the Creative Commons Attribution License (CC BY). The use, distribution or reproduction in other forums is permitted, provided the original author(s) and the copyright owner(s) are credited and that the original publication in this journal is cited, in accordance with accepted academic practice. No use, distribution or reproduction is permitted which does not comply with these terms. 